\title{
Usefulness of Free Conference Call (FCC) in Digital Learning Platform: A Comparative Study using Users' Perception and Economical Compatibility
}

\author{
Subhajit Panda \\ Assistant Librarian, Chandigarh University, Mohali, Punjab, India \\ subhajit.e9641@cumail.in
}

\begin{abstract}
The outbreak of the present pandemic coronavirus (official designation COVID-19 or SARS$\mathrm{CoV}$-2) has a clear negative impact on academic and research activities. Issues created by such pandemic viz. loss of communication; shut down of school, college and universities; disruption of the formal learning process; damage of print materials, etc. provoke the transformation of the learning process from conventional to digital. A sophisticated \& multitasking platform for online learning is the primary requirement of this transformation, which conforms to the 5A's of access, i.e., Availability, Adequacy, Accessibility, Affordability, and Appropriateness. It bridges the digital divide by ensuring equal access to the web for all. In this paper, the authors have conducted a comparative analysis between the most commonly used web-conferencing tools (viz. FCC, ZOOM, GTM, Join.me \& Cisco WebEx) in India, both in terms of users' \& economic perspective. The Users' perspective was determined by conducting a short online survey using a Google form questionnaire. The survey contains 450 respondents equally distributed among three sample groups, viz. Students, faculty members \& library professionals. And the Economical compatibility is identified by solely using the tools \& check their pricing \& plans. After evaluation \& comparison, the study identified that the tool FCC (Free Conference Call), can use by learners and educators as an alternative solution to the physical classroom. This is a dissemination or sharing platform and the most versatile and comprehensive free web-conferencing solution which can be used by academic institutions and educators for online classes. Besides, this paper also goes through a basic overview of 5 A's of access and provides sufficient evidence that FCC meets all the five criteria of accessibility to clarify the judgment of its acceptance.
\end{abstract}

Keywords: 5A's of access, COVID-19, Digital divide, Digital learning, Free Conference Call (FCC), ZOOM, GTM, Join.me, Cisco WebEx, Web conferencing

\section{Introduction}

The spread of the novel coronavirus COVID-19 has wreaked havoc on social contact and organization worldwide, and the education sector is no exception [1]. Both the direct and indirect effects of education are a subject risk to such a pandemic. This COVID-19 pandemic is neither the first and confidently nor the last epidemic that will pose a threat to the conventional education system. Instead, efforts should be made to find measures that can ensure the continuation of the education system for posterity. The virtual online classroom may be an

Article history:

Received (February 17, 2021), Review Result (March 15, 2021), Accepted (April 16, 2021) 
alternate solution to this problem which offers many benefits. Such a transition is difficult in India because Indian students and academicians are more accustomed to the conventional classroom-based study system. Sometimes their knowledge and skill also not efficient enough with the online teaching-learning environment. In such a scenario, Indian users find it difficult to choose the best and most affordable platform as per their requirements. To address this problem, the current study compared the most widely used web-conferencing tools in India (FCC, ZOOM, GTM, Join.me, and Cisco WebEx) from both a user and a financial standpoint.

\section{Statement of the problem}

Because of these unprecedented times of COVID-19 Pandemic, the recent UGC circular (dated 1st July 2020) issued to the Vice-Chancellors of all the Universities having Human Resource Development Centres (HRDCs) regarding "Conduct of courses/programmes in Online Mode" [2]. In addition to the Online Courses, all the HRDCs shall also organize Capacity Building Short-term Training Programs for Teachers on Using ICT for Online Teaching-Learning Process. As a pre-requisite for switching over to online mode, it has to be understood that online education is a viable tool for reaching a large number of participants. Such virtual learning systems should have visual appeal making online classes an inviting, pleasant place to be. Participants need to be sensitized in advance through introductory lectures relating to MOOCS and online delivery mode-related challenges in pedagogy for continued interest in these programmes along with their solutions. Resource persons shall be able to present text, videos, or links to other sources downloadable by the participants. Engaging the learner participant in conversations and increasing collaboration through discussion with resource persons and peer-to-peer support anytime, anywhere [3]. As in India conventional learning process is more common than the online one. At the primary stage of lockdown, it creates a tremendous problem for many academicians who can't cope up with this uncertain change. During the transition time of pandemic crises, commit to continuous improvement by diligent pre-preparation and execution. Handling a small class or an educational event with fewer participants can be efficiently done using popular applications such as Zoom, CiscoWebEx, Google Meet, and others. Any educational event with a large number of participants, on the other hand, necessitates paid facilities, which might not be affordable to all HEIs, including colleges and universities. The academicians \& students are not capable of select the best tools as per their requirement. In this context, this paper provides a brief comparison among commonly known video-conferencing tools and also suggests the best. It should specify that the evaluation $\&$ suggestions are purely basis on their price, usability \& availability of features; variation may occur.

\section{The literature review}

Learning is more effective, interactive, broad, not time-bound, and not patterned only in the classroom [4]. For understanding the increasing use of video-conferencing tools, and their benefits to improve the quality of education, here we discussed some prominent literature that visualizes the use of video-conferencing tools and technologies in the present situation of the pandemic COVID-19.

In their paper Lapitan et al., [5] discussed the shift to distance teaching and learning during the COVID-19 pandemic, its challenges \& difficulties, and the use of video-conferencing tools e.g., Zoom or Google Meet for conducting the synchronous part of the teaching. Akers et al. [6] examined the acceptance of MR spatial computing (Magic Leap One headsets) using an avatarmediated social interaction application (Spatial) over traditional 2D teleconferencing software 
while adapting a fully remote classroom environment. Rahimi and Martin [7] identified the challenges that arise due to the certain closure of educational institutions during the COVID19 pandemic and also suggest some strategies incorporating the use of learning management systems, web conferencing software, and open-source software to mitigate these challenges. Zao, Zhao and Siau [8] applied the eLearning usability heuristics to evaluate the major video conferencing platforms (e.g., Cisco WebEx, Microsoft Teams, and Zoom). Xuedong et al. [9] showed significant differences for Email, WhatsApp, and LandLine for contacting during corona days, and Video Conferencing technology (e.g., Microsoft team, Zoom, TalnetLMS, Schoology) used for distance learning. It not only helps policymakers in selecting the best technology for teaching during corona days but also helps universities in attracting and retention students through the use of technology. Khatib [10] carried out a literature review focused on examining the potential of three different forms of video conferencing systems: Desktop Video Conferencing (VCM), Interactive Video Conferencing (VCI), and Web Video Conferencing (VCW) to provide an accessible and comprehensive learning experience before the outbreak of COVID-19. Umacharan, Said, and Estabraq [11] discussed the broadcasting platforms e.g., Google meet, Teems, WebEx, Hangouts, Zoom, FreeConferenceCall to distant locations through video performances and also through indigenously advanced conferencing platforms stand allied to complete with the internet, converting distance education or e-learning as forthcoming cardinal erudition. The survey of Bui et al., [12] presented the behavioural intention of Vietnamese female students $(\mathrm{N}=254)$ to use video conferencing tools (VCTs; e.g., Zoom, Microsoft Teams, or Google Hangout) in the COVID-19 pandemic. Similarly, AlMaroof et al., [13] attempted to explore the effect of Google Meet acceptance among Arab students $(\mathrm{N}=475)$ during the pandemic in Oman, UAE, and Jordan.

\section{Study rationale}

All of the above studies discussed some of the useful \& familiar video-conferencing tools and their usage benefits during coronavirus lockdown in teaching-learning platforms. However, it can be identified that no such study has been conducted to test, evaluate, compare, analyze and recommend the most affordable platform for helping institutions and organizations with inadequate financial resources for acquiring such web-conferencing platform/software in facing this abrupt outburst of e-learning after the COVID-19 eruption. Moreover, the addition of actual users' perspective and economical compatibility gives the study an extra value \& significance.

The study discusses the features of the web-conferencing tool FCC vis-a-vis other paid tools in the light of the 5A's of access, i.e., Availability, Adequacy, Accessibility, Affordability, and Appropriateness. The other tools used for comparison include GotoMeeting (GTM), Zoom, and Join.me. Wherever possible step-by-step procedure of using FCC for hosting live events like an online class, virtual meetings, etc., and other features have been provided.

The study objectives include:

To evaluate the features of FCC including Hosting, Screen share, Video conference, Chat, Screen Recording, Broadcaster, and Integrations

To illustrate the features of Desktop App, Web App, and Mobile App.

To compare the features of FCC with other proprietary solutions like Zoom. GTM and Join.me.

\section{Methodology}


The research design of the current research was structured upon the investigation of two research problems based on users' perspective and economical perspective. The Users' perspective was determined by conducting a short survey. The survey questionnaire was designed upon a structured research questionnaire created through Google Form (https://forms.gle/6p94MVp1ezggXi8m7) and circulated online via email to the targeted sample groups viz, Students, Faculty Members \& Library Professionals of all over India. It took almost one month and distributed among 600 (almost) targeted sample groups of which 491 (98\%) took part in this survey from a different region of India. Among which 450 (i.e., 150 for each single sample type) was selected as the final sample.

The market is overloaded with different web-conferencing tools, all of which have a price tag not aligning with the purchasing power of low-budget small organizations. The second part of the study was conducted to identify a versatile, comprehensive, and pocket-friendly elearning/webinar/online meeting solution. User accounts were created in several videoconferencing platforms including Zoom, GoToMeeting (GTM), Join.me, FCC, Cisco WebEx, etc. Desktop app, as well as mobile apps, were installed. Testing and evaluation were done for each shortlisted platform on all the versions, i.e., web, desktop as-well-as m-app. Feature comparisons were made considering the subscription cost. To identify the most affordable and multi-functional tool, comparative tables were made. Selection criteria used include a maximum number of concurrent participants that could be accommodated simultaneously, the maximum duration for which the online session could be extended, security features, ease of hosting and use, reporting, etc.

\section{Data analysis}

Data analysis and interpretation hold a crucial position in the research process. In the case of Survey Data, after the data collection, it was imported as a .csv file (Google sheet) for further analysis and visualization using spreadsheet software. Finally, the data analysis for the present research was done quantitatively with the help of both descriptive statistics and inferential statistics. It aims to organize, classify and summarize the data being collected for better comprehension and interpretation leading to understand and explore answers or solutions to the research problem which originally triggered the research. Data about the Economical Perspective of the study collected after analyzing each available \& common feature of the target web-conferencing solution \& their pricing structure.

\section{Results analysis}

The comparison among the selected web-conferencing tools is done using users' perspectives and economic factors as comparative parameters. The respondents of the varied disciplines may exhibit a wide range of attributes, behaviours, experiences, incidents, qualities, situations, and so forth which facilitates gaining greater insights understanding the variation in users' perspectives.

\subsection{User's perspective}

A tool's effectiveness and efficiency can be measured by its functionality and services, but its actual output can only be determined by the user's viewpoint. As a result, the user's perspective is the most critical parameter to consider when evaluating a tool, as it is the only way to determine the tool's usability. The results of the user survey among the target sample classes, namely students, faculty members, and library professionals, are shown in [Table 2]. 
Table 1. Comparative chart according to users' perspective

\begin{tabular}{|c|c|c|c|c|c|c|c|c|c|c|c|c|c|c|c|c|}
\hline \multirow[b]{2}{*}{$\mathbf{S N}$} & & \multicolumn{3}{|c|}{ FCC } & \multicolumn{3}{|c|}{ Zoom } & \multicolumn{3}{|c|}{ GTM } & \multicolumn{3}{|c|}{ Join.me } & \multicolumn{3}{|c|}{ Cisco Webex } \\
\hline & & $\mathbf{S}$ & $\mathbf{F}$ & $\mathbf{L P}$ & $\mathbf{S}$ & $\mathbf{F}$ & LP & $\mathbf{S}$ & $\mathbf{F}$ & $\mathbf{L P}$ & $\mathbf{S}$ & $\mathbf{F}$ & $\mathbf{L P}$ & $\mathbf{S}$ & $\mathbf{F}$ & $\mathbf{L P}$ \\
\hline \multicolumn{17}{|c|}{ Rating } \\
\hline 1 & $\begin{array}{c}\text { Meets } \\
\text { Requirements }\end{array}$ & 4.71 & 4.67 & 4.91 & 4.67 & 4.64 & 4.79 & 4.58 & 4.47 & 4.63 & 4.46 & 4.38 & 4.56 & 4.57 & 4.55 & 4.59 \\
\hline 2 & Ease of Use & 4.89 & 4.91 & 4.82 & 4.64 & 4.87 & 4.52 & 4.40 & 4.38 & 4.36 & 4.52 & 4.69 & 4.55 & 4.69 & 4.60 & 4.63 \\
\hline 3 & Ease of Setup & 4.99 & 5.00 & 5.00 & 4.82 & 4.85 & 4.89 & 4.35 & 4.63 & 4.39 & 4.53 & 4.69 & 4.47 & 4.43 & 4.55 & 4.49 \\
\hline 4 & Ease of Admin & 4.78 & 4.69 & 4.81 & 4.66 & 4.57 & 4.67 & 4.02 & 4.33 & 4.43 & 4.47 & 4.59 & 4.54 & 4.54 & 4.51 & 4.50 \\
\hline 5 & Quality of Support & 4.45 & 4.44 & 4.55 & 4.30 & 4.29 & 4.21 & 4.12 & 3.69 & 4.02 & 4.01 & 4.11 & 4.07 & 4.33 & 4.35 & 4.15 \\
\hline 6 & $\begin{array}{l}\text { Ease of Doing } \\
\text { Business With }\end{array}$ & 5.00 & 5.00 & 5.00 & 4.66 & 4.85 & 4.85 & 4.42 & 4.35 & 4.31 & 4.20 & 4.29 & 4.38 & 4.32 & 4.48 & 4.30 \\
\hline 7 & $\begin{array}{l}\text { Product Direction } \\
\text { (\% positive) }\end{array}$ & 4.54 & 4.17 & 4.81 & 4.59 & 4.24 & 4.76 & 3.66 & 3.83 & 4.09 & 4.13 & 3.97 & 4.09 & 4.11 & 4.14 & 4.13 \\
\hline \multicolumn{17}{|c|}{ Features } \\
\hline A. & $\begin{array}{c}\text { Collaboration } \\
\text { Tools }\end{array}$ & & & & & & & O & & & & & & & & \\
\hline 1 & Screen Sharing & 4.87 & 4.91 & 4.67 & 4.97 & 4.89 & 4.87 & 4.59 & 4.53 & 4.43 & 4.64 & 4.64 & 4.54 & 4.75 & 4.78 & 4.76 \\
\hline 2 & Presentation & 4.83 & 4.80 & 4.75 & - & - & - & 4.65 & 4.54 & 4.45 & 4.60 & 4.55 & 4.57 & 4.67 & 4.65 & 4.58 \\
\hline 3 & Whiteboarding & 4.39 & 4.58 & 4.37 & - & - & - & 4.19 & 4.47 & 4.01 & 4.71 & 4.73 & 4.81 & 4.33 & 4.33 & 4.31 \\
\hline 4 & Live Chat & 3.70 & 3.71 & 4.29 & 4.81 & 4.79 & 4.84 & 4.44 & 4.27 & 4.54 & 4.82 & 4.77 & 4.79 & 4.51 & 4.57 & 4.56 \\
\hline 5 & Hand Rise & 4.59 & 4.27 & 4.70 & 4.73 & 4.07 & 4.83 & 4.67 & 4.56 & 4.75 & - & - & - & 4.63 & 4.59 & 4.60 \\
\hline B. & $\begin{array}{c}\text { Meeting } \\
\text { Coordination }\end{array}$ & & & & & & & & & & & & & & & \\
\hline 1 & Sheduling & 4.64 & 4.49 & 4.67 & 4.80 & 4.57 & 4.99 & 4.52 & 4.53 & 4.61 & 4.60 & 4.49 & 4.62 & 4.56 & 4.57 & 4.57 \\
\hline 2 & Recording & 4.67 & 4.62 & 4.37 & 4.78 & 4.85 & 4.75 & 4.32 & 4.29 & 4.27 & 4.52 & 4.48 & 4.44 & 4.56 & 4.64 & 4.53 \\
\hline 3 & $\begin{array}{l}\text { Participant } \\
\text { Permissions }\end{array}$ & 4.85 & 4.65 & 4.86 & 4.90 & 4.81 & 4.60 & 4.43 & 4.51 & 4.41 & 4.62 & 4.55 & 4.68 & 4.61 & 4.59 & 4.67 \\
\hline 4 & One-Click Join & 3.07 & 3.31 & 3.26 & 3.67 & 3.96 & 3.87 & 3.61 & 3.54 & 3.52 & 4.59 & 4.70 & 4.65 & 4.48 & 4.49 & 4.53 \\
\hline C. & Software Type & & & & & & & & & & & & & & & \\
\hline 1 & Mobile Application & 4.45 & 4.34 & 4.44 & 4.64 & 4.59 & 4.87 & 4.10 & 4.18 & 4.14 & 4.14 & 4.17 & 4.21 & 4.31 & 4.33 & 4.33 \\
\hline 2 & $\begin{array}{c}\text { Browser } \\
\text { Application }\end{array}$ & 4.43 & 4.66 & 4.64 & 4.62 & 4.71 & 4.72 & 4.00 & 4.08 & 4.10 & 4.45 & 4.53 & 4.48 & 4.15 & 4.12 & 4.21 \\
\hline 3 & $\begin{array}{l}\text { Desktop } \\
\text { Application }\end{array}$ & 4.52 & 4.80 & 4.73 & 4.45 & 4.81 & 4.87 & 4.41 & 4.38 & 4.45 & 4.44 & 4.46 & 4.57 & 4.43 & 4.80 & 4.73 \\
\hline
\end{tabular}

*Notations: S- Student, F- Faculty Member, LP-Library Professionals **Shaded areas denote the top scorer of that particular

The survey findings show that among the 19 different types of parameters and 57 positions (considering three different types of respondents) structured in the questionnaire, FCC secures top place with 11 different types and 26 positions. Zoom, on the other hand, secures the second position with 10 different types and 23 unique positions. In the case of features under 'Rating', 
FCC solely dominates others but have weakness in some specific features viz, 'Live Chat' and 'One-Click Join. While Zoom selected as best in 'Meeting Coordination' \& 'Software Types', but don't possess 'Presentation' and 'Whiteboarding' features. Again, Join.me in particular identified as best in features like 'Whiteboarding' an 'One-Click Join'. Overall, the result indicates that in India users of all categories select FCC as the most effective web-conferencing tool.

\subsection{Economical compatibility}

Economical compatibility or economic perspective or economic way of thinking; including definitions of scarcity, opportunity cost, purposeful behavior, utility, marginal analysis (benefits and costs), and how these concepts may be used in decision-making [14][pp. 3-25]. In the case of developing countries like India, an economic perspective is important while selecting a tool for web-conferencing. So, in the second stage of the study compare affordability among the targeted web-conferencing tools. The result of the comparative analysis is tabulated under the following table 3 and divided into 6 sections according to the nature of the specific features. [15][16][17][18][19]

Table 2. Comparative chart according to economical compatibility

\begin{tabular}{|c|c|c|c|c|c|}
\hline Feature/Function & $\mathrm{FCC}$ & GTM & Zoom & Join.me & Cisco Webex \\
\hline \multicolumn{6}{|l|}{ A. Services } \\
\hline Audio conferencing & $\begin{array}{l}\text { 1,000 FREE } \\
\text { Participants } \\
\text { VoIP: included } \\
\text { Toll: included }\end{array}$ & \begin{tabular}{|c|}
50 free \\
participants (14- \\
day trial) \\
VoIP: included \\
Toll: included \\
\end{tabular} & $\begin{array}{c}50 \text { free } \\
\text { participants } \\
\text { (14-day trial) }\end{array}$ & $\begin{array}{l}50 \text { free participants } \\
\text { (14-day trial) }\end{array}$ & $\begin{array}{c}100 \text { free participants } \\
\text { (14-day trial) } \\
\text { VoIP: included } \\
\text { Toll: included }\end{array}$ \\
\hline Video conferencing & $\begin{array}{l}\text { 1,000 FREE } \\
\text { Participants }\end{array}$ & \begin{tabular}{|c|}
50 free \\
participants (14- \\
day trial) \\
\end{tabular} & $\begin{array}{c}100 \text { free } \\
\text { participants }\end{array}$ & $\begin{array}{l}10 \text { free participants } \\
\text { (14-day trial) }\end{array}$ & 100 free participants \\
\hline Screen sharing & $\begin{array}{l}\text { 1,000 FREE } \\
\text { Participants }\end{array}$ & \begin{tabular}{|c|}
50 free \\
participants (14- \\
day trial)
\end{tabular} & $\begin{array}{c}100 \text { free } \\
\text { participants }\end{array}$ & $\begin{array}{l}10 \text { free participants } \\
\text { (14-day trial) }\end{array}$ & 100 free participants \\
\hline Time restrictions & 6 Hours & $\begin{array}{l}\text { Unlimited (14- } \\
\text { day trial) }\end{array}$ & 40 minutes & $\begin{array}{l}\text { Unlimited (14-day } \\
\text { trial) }\end{array}$ & 50 minutes \\
\hline \multicolumn{6}{|c|}{ B. Audio Conferencing Features } \\
\hline \begin{tabular}{|l|} 
International dial-in \\
numbers
\end{tabular} & Free & $\$$ & $\$$ & $\$$ & $\$$ \\
\hline \begin{tabular}{|l|l} 
Web controls \\
\end{tabular} & Free & $\$$ & Free & $\$$ & $\$$ \\
\hline Breakout rooms & Free & $\mathrm{x}$ & Free & $\$$ & Free \\
\hline Radio streaming & Free & $\mathrm{x}$ & $\mathrm{x}$ & $\mathrm{x}$ & $\$$ \\
\hline \multicolumn{6}{|c|}{ C. Video Conferencing Features } \\
\hline Multi-video feed & Free & $\$$ & $\mathrm{x}$ & $\$$ & $\$$ \\
\hline \begin{tabular}{|ll} 
Active speaker \\
technology
\end{tabular} & Free & $\mathrm{x}$ & $\$$ & $\mathrm{x}$ & $\$$ \\
\hline Join as view-only & Free & $\mathrm{x}$ & $\$$ & $\mathrm{x}$ & Free \\
\hline Join by telephone & Free & $\$$ & $\$$ & $\$$ & $\$$ \\
\hline
\end{tabular}




\begin{tabular}{|c|c|c|c|c|c|}
\hline Switch presenter & Free & $\$$ & Free & $\$$ & $\$$ \\
\hline Remote control & Free & $\$$ & Free & $\$$ & $\$$ \\
\hline Whiteboarding & Free & $\$$ & Free & $\$$ & Free \\
\hline \multicolumn{6}{|l|}{ E. Recording } \\
\hline $\begin{array}{|lr|}\begin{array}{l}\text { Audio, } \\
\text { screen }\end{array} & \text { video, and } \\
\text { recording } & \text { sharing } \\
\end{array}$ & Free & $\$$ & Free & $\$$ & Free \\
\hline Create presentations & Free & $\mathrm{x}$ & $\$$ & $\mathrm{x}$ & $\$$ \\
\hline $\begin{array}{l}\text { Easy download, } \\
\text { playback, and share }\end{array}$ & Free & $\$$ & $\$$ & $\$$ & Free \\
\hline Broadcaster & Free & $\mathrm{x}$ & $\$$ & $\mathrm{x}$ & $\$$ \\
\hline $\begin{array}{l}\text { Library of recorded } \\
\text { files }\end{array}$ & Free & $\mathrm{x}$ & $\$$ & $\mathrm{x}$ & $\$$ \\
\hline Keywords & Free & $\mathrm{x}$ & $\mathrm{x}$ & $\mathrm{x}$ & $\mathrm{x}$ \\
\hline \begin{tabular}{|l} 
Automatic \\
transcriptions
\end{tabular} & Free & $\mathrm{x}$ & $\mathrm{x}$ & $\mathrm{x}$ & $\mathrm{x}$ \\
\hline Storage & 1 GB Free & $\$$ & $\$$ & $\$$ & $\$$ \\
\hline \multicolumn{6}{|l|}{ F. Additional features } \\
\hline Site customization & Free & $\$$ & $\$$ & $\$$ & $\$$ \\
\hline File upload & Free & $\$$ & $\$$ & $\$$ & $\$$ \\
\hline Security & Free & $\$$ & Free & $\$$ & $\$$ \\
\hline Chat & Free & $\$$ & Free & $\$$ & Free \\
\hline Q\&A & Free & $\$$ & $\$$ & $\$$ & Free \\
\hline Mobile access & Free & $\$$ & $\$$ & $\$$ & Free \\
\hline $\begin{array}{|lr|}\text { No } & \text { participant } \\
\text { downloads } & \text { (Web } \\
\text { Viewer) } & \\
\end{array}$ & Free & $\$$ & $\$$ & $\$$ & $\$$ \\
\hline 24/7 Customer Care & Free & Free & $\$$ & $\$$ & $\begin{array}{c}\text { Online } \\
\text { support only }\end{array}$ \\
\hline
\end{tabular}

According to [Table 2], for the features under 'Services', FCC provides several times better opportunities with free services than the other selected alternatives. All other mentioned features (B-F) are free for FCC only there is a free storage limitation of 1 GB. For the ZOOM solution, the maximum benefits can be obtained in 14 days free trial period where it allows 50 participant audio-conferencing, 100 participants for video conferencing \& screen sharing with 40 minutes time limitation for every lecture. Among other features, only 7 are free for this free trial. GTM provides only 50 participants for Audio, Video \& Screen Sharing, but for an unlimited time within 14 days trial, with only free Customer Care support in addition. While, Join.me facilitates 50 participants for Audio conferencing and 10 participants for Video conferencing \& Screen sharing, with no time limit for a single lecture for 14 days free trial. The 14 days free trial of Cisco WebEx provides 100 participants for Audio \& Video conferencing and screen sharing, with 50 minutes time limitations.

The result displays those unavailability advertisements, quality issues, hidden fees, sales pitches, contracts, purchase requirements, privacy issues, restrictions, and paid surprises; the 
FCC offers a truly free service and not a free trial for a certain duration. Accounts created on FCC never expire and one account can be used for an unlimited number of classes. FCC provides Call Detail Report (CDR) after every class and web conferencing via the email of the educator and which is very useful to analyze how students progress in the class and automatically marks the attendance. The report includes participant information such as time spent on each call and other meeting details. In a single conference call, FCC can accommodate a maximum of 1,000 participants. It also offers paid large meeting services allowing up to 5,000 participants. An event duration has a limit of six hours with an unlimited number of calls allowed. It has the feature of canceling static or echo on a conference call. FCC provides the benefit of collaborative video and screen sharing and increases productivity.

In an FCC virtual session [20],

- hosts can access call controls on FCC, see the call list, display video, and share computer screens, documents, web links, or presentations.

- hosts can mute an individual participant using the Web Controls panel located on the Meeting Wall or the Meeting Dashboard by selecting a participant from the Attendee List and click Mute.

- hosts can click Chat on the Meeting Dashboard to message the whole group or private message an individual participant.

Also, FCC is compatible with a wide variety of devices and platforms for online webinars including PCs, Macs ${ }^{\circledR}$, Chromebooks ${ }^{\mathrm{TM}}$, iOS, and Android ${ }^{\mathrm{TM}}$ phones and tablets and also provides the facility of Remote desktop access [21].

\section{Findings and limitations}

(1) The findings of the study both in terms of users' perspective \& economical compatibility recommend that FCC can be used by the HEIs and HRDs for conducting online classes, FDPs, RCs, OCs, and STTPs effectively, conveniently, and securely with high affordability.

(2) FCC provides the Desktop app, web app as well-as mobile app making a wider choice available for the host and the participants.

(3) FCC is available on multiple OS platforms including macOS®, Windows, and Linux.

(4) As a mobile app, FCC is available for free download on Android and iOS platforms.

(5) FCC integrates with Google and Outlook Calendar through free download extension/Plug-in.

(6) "FreeConferenceCall.com Scheduler" Chrome Extension for Google Calendar" provides a quick and easy way to schedule a virtual meet by creating an event. Users can join the meeting or host one from the Google Calendar event.

The findings of the study completely structured upon the above findings but with some specified criteria. The research began with a focus on the free or trial versions of FCC, as well as all other alternatives. So, the result of the findings shows a comparison between FCC and the free versions or trial versions of each of the solutions. If we consider the pro versions of the other tools like ZOOM or Cisco WebEx, it may suppress FCC in terms of services \& facilities. Thus, with considering an economical overview the study identifies FCC as the most efficient $\&$ affordable web-conferencing tool. Again, the study has also a geographical limitation, i.e., only based on the viewpoint of the Indian user.

\section{FCC and 5 A's of access}

The base of this paper depends on the primary requirements of internet facility and knowledge of access in the web i.e., Digital Literacy. The term "digital literacy" is used to 
describe the ability to harness the potential of digital tools [22]. In the process of transmission, the learning process from conventional to digital equal access of web is also necessary because as of the print material web also demands money for getting access and which creates a void between the research and researcher, information and seeker, educator and learner, query and the solutions. In the last decades, efforts to bridge the digital divide have focused on access, i.e., ensuring that everyone is connected to the internet. Inequalities remain though: over half the world population still doesn't have internet access, mostly underprivileged individuals in both developing countries and industrialized countries. The last few years, in particular with the emergence of e-government initiatives, made it clear that accessibility is as important an issue [23]. The 5A's of access gives a theoretical framework of this bridging of the digital divide. Which include,

Table 3. FCC and 5 A's of access [24]

\begin{tabular}{|c|c|c|}
\hline $\mathrm{SN}$ & The 5 As & FCC \\
\hline A1 & Availability & $\begin{array}{l}\text { Whether services are available in the first place. For FCC availability, the FCC server } \\
\text { health was tested using https://uptime.com. The result, as displayed in fig. 1, depicts } \\
\text { high web server availability. Thus, FCC meets the }\end{array}$ \\
\hline $\mathrm{A} 2$ & Adequacy & $\begin{array}{l}\text { Whether there is an adequate and continued supply of available services. The } \\
\text { comparison table 2, depicts the adequacy of FCC owing to its richness of features even } \\
\text { in its free version with the capability of accommodating } 1000 \text { users and } 6 \text { hours of } \\
\text { generous meeting duration. }\end{array}$ \\
\hline A3 & $\begin{array}{c}\text { Accessibilit } \\
\mathrm{y}\end{array}$ & $\begin{array}{l}\text { Whether the services are effectively available for utilization. FCC is available for all } \\
\text { the popular OSS including macOS } \AA \text {, Windows, and Linux. For mobile devices, FCC } \\
\text { has its presence for Android }{ }^{\mathrm{TM}}, \mathrm{iPhone} \AA, \mathrm{Pad} \AA \text { or } \mathrm{PPad} \text { Pro } \AA \text {. It supports wide } \\
\text { Integrations with Google Calendar, Microsoft Outlook Calendar, Slack, Dropbox, and } \\
\text { Evernote. Thus, it can be inferred that FCC is Accessible. The availability of a free } \\
\text { version also endorses this point. }\end{array}$ \\
\hline A4 & $\begin{array}{c}\text { Affordabilit } \\
\text { y }\end{array}$ & $\begin{array}{l}\text { Affordability refers to the removal of financing burden for availing any important } \\
\text { service or solution and the product has its reach to the masses including those lacking } \\
\text { higher purchasing power. FCC fulfills these criteria as it allows its free usage without } \\
\text { financial obligation. }\end{array}$ \\
\hline A5 & $\begin{array}{l}\text { Appropriate } \\
\text { ness }\end{array}$ & $\begin{array}{l}\text { Service/product available must be relevant and useful to the user as well as } \\
\text { organizational needs and it should lead to meaningful and satisfactory outcomes. Here } \\
\text { also, FCC qualifies owing to the provision of all the major requirements of a webinar } \\
\text { or meeting as evident from the comparison table with the other such tools. Multiple } \\
\text { device support also strengthens this aspect. }\end{array}$ \\
\hline
\end{tabular}

The analysis of the paper suggests that web-conferencing tool FCC satisfies all the 5A's of access and prove its impacts not only on academic and professional achievement, cognitive development but also on social inclusion, empowerment, and citizenship, advocating for the inclusion of a digital literacy capacity-building strategy for all in e-governments initiatives.

\section{Implication}


21 st Century teaching and learning strategies related to the various methods used include the use of appropriate tools with the latest technological developments to help students to understand clearly the content of the subject [25]. But still, people resist change without understanding the need and importance of it, and when a situation arises, all should adapt to change willingly and unwillingly. This was the situation that occurred to the teaching fraternity too. Indian higher education institution has used various pedagogy for innovation, development, and engagement of students. Many faculties have resisted the change when they had been asked to take virtual classes for students. And a couple of training was provided by the management of the institutions hence faculty will not face any difficulties on the same. As everything exists in the mindset, the mindset has to be changed towards the adoption and adaption of virtual classrooms and adopt technology for the betterment of students [26].

\section{Conclusion}

In the current e-centric world every minute of a day we're living during a data explosion and have a very short time to analyze information, misinformation \& disinformation before making a decision. Moreover, as in India online study system and the use of the web-conferencing tools is not so common for the student, faculty member, as well as library professionals; one user can easily be confused and overwhelmed with so many options, and how to identify the best solution [27]. To solve this specified problem, the current study thoroughly compared commonly used web-conferencing tools in India, both in terms of Users' perspective \& Economical compatibility. And, the result suggests the quality of FCC services can be more than a match for paid counterparts. Moreover, FCC is a tool that conforms to 5A's of access i.e., Availability, Adequacy, Accessibility, Affordability, and Appropriateness; that bridges the digital divide by ensuring equal access to the web for all. Again, though the study provides an overview of the selection criteria of a web-conferencing tool but also lacks its appropriateness in some points like regional limitations and the targeted sample versions. Last, it can be said that in a situation of such disaster like the recent outbreak of COVID-19, such study helps us to fight against the transformation from a conventional to a digital way of learning and suggest that educators \& learners must be ready to adopt new changes and requirement of the present situation.

\section{References}

[1] M. P. A. Murphy, "COVID-19 and emergency eLearning: Consequences of the securitization of higher education for post-pandemic pedagogy," Contemporary Security Policy, vol.41, no.3, pp.1-14, Apr. (2020) DOI: $10.1080 / 13523260.2020 .1761749$

[2] University Grants Commission, "Notification | The gazette of India: Extraordinary," Jan. (2020) [Online]. Available: https://www.ugc.ac.in/pdfnews/6758108_Online-Amendment-Regulation.pdf.

[3] University Grants Commission, "Notification | The gazette of India: Extraordinary," Jul. (2018) [Online]. Available: https://www.ugc.ac.in/pdfnews/7553683_Online-Courses-or-ProgrammesRegulations_2018.pdf

[4] E. Grabowski et al., "Analyse des Stellenwertes von, eLearning," in der Augenheilkunde und Evaluierung einer, eLearning-App, Der Ophthalmologe, Apr. (2020) DOI: 10.1007/s00347-020-01100-x.

[5] L. D. Lapitan, C. E. Tiangco, D. A. G. Sumalinog, N. S. Sabarillo, and J. M. Diaz, "An effective blended online teaching and learning strategy during the COVID-19 pandemic," Education for Chemical Engineers, vol.35, pp.116-131, Apr. (2021) DOI: 10.1016/j.ece.2021.01.012

[6] J. Akers, J. Zimmermann, L. Trutoiu, B. Schowengerdt, and I. Kemelmacher-Shlizerman, "Mixed reality spatial computing in a remote learning classroom," presented at the 6th ACM Symposium on Spatial User Interaction, SUI 2020, Canada, Oct. (2020) DOI: 10.1145/3385959.3422705 
[7] N. Rahimi and N. L. Martin, "Challenges and strategies for online teaching in information technology and other computing programs," presented at the 21 st Annual Conference on Information Technology Education, SIGITE 2020, United States, Oct. (2020) DOI: 10.1145/3368308.3415369

[8] C. Zou, W. Zhao, and K. Siau, "COVID-19 pandemic: A usability study on platforms to support eLearning," in Communications in Computer and Information Science, Copenhagen, Denmark, vol.1294, pp.333-340, Jul. (2020) DOI: 10.1007/978-3-030-60703-6_43

[9] G. Xuedong, S. H. Qureshi, G. Ali, and A. Bhatti, "Towards an analysis of best teaching technology during corona days," Revista Argentina de Clinica Psicologica, vol.29, no.4, pp.21-31, (2020) DOI: $10.24205 / 03276716.803$

[10] A. S. E. Khatib, "Videoconferencing classes: A solution to the social distance caused by COVID-19 or a big problem?” Jun. (2020) DOI: 10.1590/scielopreprints.787

[11] K. Umachandran, M. Said, and R. Estabraq, “The digital age learning for industries," (2020) [Online]. Available: https://www.researchgate.net/publication/344135504

[12] T.-H. Bui, D.-H. Luong, X.-A. Nguyen, H.-L. Nguyen, and T.-T. Ngo, "Impact of female students' perceptions on behavioural intention to use video conferencing tools in COVID-19: Data of Vietnam," Data in Brief, vol.32, no.2, pp.106142, Oct. (2020) DOI: 10.1016/j.dib.2020.106142

[13] R. S. Al-Maroof, M. T. Alshurideh, S. A. Salloum, A. Q. M. AlHamad, and T. Gaber, "Acceptance of google meet during the spread of coronavirus by Arab university students," Informatics, vol.8, no.2, pp.1-17, Mar. (2021) DOI: 10.3390/informatics 8020024

[14] S. L. Brue and C. R. McConnell, "Essentials of economics, chapter 1: Limits, alternatives, and choices, 4th ed.”, New York City, United States: McGraw-Hill/Irwin, (2005) pp.3-25

[15] FreeConferenceCall, "Features FreeConferenceCall.com," https://www.freeconferencecall.com/global/in/ features (Accessed Apr. 8, 2021)

[16] GoToMeeting, "Online meeting software, video conferencing and web conferencing - try free | GoToMeeting," https://www.gotomeeting.com/en-in (Accessed Apr. 8, 2021)

[17] Zoom, "Video Conferencing, Web Conferencing, Webinars, Screen Sharing," (2018), https://zoom.us/ (Accessed Apr. 8, 2021)

[18] Join.me, “Audio and video conferencing features | join.me,” https://www.join.me/en/features (Accessed Apr. $8,2021)$

[19] Cisco WebEx, “Cisco webEx plans and pricing," https://www.webex.com/pricing/index.html (Accessed Apr. $8,2021)$

[20] FreeConferenceCall, "Host Instructions | FreeConferenceCall.com,” https://www.freeconferencecall.com/hostinstructions (Accessed Apr. 11, 2021)

[21] FreeConferenceCall, "Support | FreeConferenceCall.com," https:/www.freeconferencecall.com/global/ support (Accessed Apr. 11, 2021)

[22] IFLA, "IFLA -- IFLA statement on digital literacy (18 August 2017)," Aug. 18, (2017), https://www.ifla.org/publications/node/11586 (Accessed Apr. 14, 2021)

[23] J. Lachal and M.-C. Peich, "Bridging the digital divide: A prerequisite for global eGovernment," Aug. (2018), Accessed: Apr. 10, 2021. [Online]. Available: http://library.ifla.org/2210/1/233-lachal-fr.pdf

[24] Patient Access Partnership, “5A's of Access,” https://www.eupatientaccess.eu/page.php?i_id=19 (Accessed Apr. 10, 2021)

[25] O. Ovcharuk, I. Ivaniuk, N. Soroko, O. Gritsenchuk, and O. Kravchyna, "The use of digital learning tools in the teachers' professional activities to ensure sustainable development and democratization of education in European countries," E3S Web of Conferences, vol.166, pp.10019, (2020) DOI: 10.1051/e3sconf/202016610019

[26] V. Shenoy, S. Mahendher, and N. Vijay, "COVID-19 lockdown technology adaption, teaching, learning, student's engagement and faculty experience,” Mukt Shabd Journal, vol.9, no.4, pp.698-702, Apr. (2020) [Online]. Available: https://www.researchgate.net/publication/340609688 
Usefulness of Free Conference Call (FCC) in Digital Learning Platform: A Comparative Study using Users' Perception and Economical Compatibility

[27] K. Kincaid, "9 myths about free conference call services and how to benefit from the facts," Jul. 15, (2016) https://www.freeconferencecall.com/resource-center/9-myths-about-free-conference-call-services-and-howto-benefit-from-the-facts (Accessed Apr. 14, 2021)

Appendix 1. FCC (Users' Survey Data)

\begin{tabular}{|c|c|c|c|c|c|c|c|c|c|c|c|c|c|c|c|c|c|c|c|}
\hline \multicolumn{20}{|c|}{ FCC } \\
\hline \multirow{2}{*}{\multicolumn{2}{|c|}{ Ratings }} & \multicolumn{6}{|c|}{ Student } & \multicolumn{6}{|c|}{ Faculty Member } & \multicolumn{6}{|c|}{ Library Professionals } \\
\hline & & 1 & 2 & 3 & 4 & 5 & Avg & 1 & 2 & 3 & 4 & 5 & Avg & 1 & 2 & 3 & 4 & 5 & Avg \\
\hline 1 & Meets Requirements & 0 & 0 & 12 & 20 & 118 & 4.71 & 0 & 0 & 0 & 49 & 101 & 4.67 & 0 & 0 & 7 & 0 & 143 & 4.91 \\
\hline 2 & Ease of Use & 0 & 0 & 0 & 16 & 134 & 4.89 & 0 & 0 & 0 & 13 & 137 & 4.91 & 0 & 0 & 12 & 2 & 136 & 4.82 \\
\hline 3 & Ease of Setup & 0 & 0 & 0 & 2 & 148 & 4.99 & 0 & 0 & 0 & 0 & 150 & 5.00 & 0 & 0 & 0 & 0 & 150 & 5.00 \\
\hline 4 & Ease of Admin & 0 & 0 & 0 & 33 & 117 & 4.78 & 0 & 0 & 10 & 26 & 114 & 4.69 & 0 & 0 & 0 & 29 & 121 & 4.81 \\
\hline 5 & Quality of Support & 0 & 0 & 9 & 65 & 76 & 4.45 & 0 & 0 & 17 & 50 & 83 & 4.44 & 0 & 0 & 5 & 58 & 87 & 4.55 \\
\hline 6 & $\begin{array}{l}\text { Ease of Doing Business } \\
\text { With }\end{array}$ & 0 & 0 & 0 & 0 & 150 & 5.00 & 0 & 0 & 0 & 0 & 150 & 5.00 & 0 & 0 & 0 & 0 & 150 & 5.00 \\
\hline 7 & $\begin{array}{l}\text { Product Direction (\% } \\
\text { positive) }\end{array}$ & 0 & 0 & 4 & 61 & 85 & 4.54 & 0 & 0 & 16 & 93 & 41 & 4.17 & 0 & 0 & 0 & 28 & 122 & 4.81 \\
\hline & Features & & & & & & & & & & & & & & & & & & \\
\hline A. & Collaboration Tools & & & & & & & & & & & & & & & & & & \\
\hline 1 & Screen Sharing & 0 & 0 & 0 & 19 & 131 & 4.87 & 0 & 0 & 2 & 9 & 139 & 4.91 & 0 & 0 & 14 & 21 & 115 & 4.67 \\
\hline 2 & Presentation & 0 & 0 & 5 & 15 & 130 & 4.83 & 0 & 0 & 0 & 29 & 121 & 4.80 & 0 & 0 & 8 & 21 & 121 & 4.75 \\
\hline 3 & Whiteboarding & 0 & 0 & 34 & 23 & 93 & 4.39 & 0 & 0 & 23 & 17 & 110 & 4.58 & 0 & 0 & 10 & 74 & 66 & 4.37 \\
\hline 4 & Live Chat & 0 & 0 & 59 & 77 & 14 & 3.70 & 0 & 0 & 64 & 66 & 20 & 3.71 & 0 & 0 & 0 & $\begin{array}{c}10 \\
7\end{array}$ & 43 & 4.29 \\
\hline 5 & Hand Rise & 0 & 0 & 11 & 39 & 100 & 4.59 & 0 & 0 & 0 & $\begin{array}{c}11 \\
0 \\
\end{array}$ & 40 & 4.27 & 0 & 0 & 0 & 45 & 105 & 4.70 \\
\hline B. & Meeting Coordination & & & & & & & & & & & & & & & & & & \\
\hline 1 & Sheduling & 0 & 0 & 8 & 38 & 104 & 4.64 & 0 & 0 & 11 & 55 & 84 & 4.49 & 0 & 0 & 0 & 49 & 101 & 4.67 \\
\hline 2 & Recording & 0 & 0 & 19 & 12 & 119 & 4.67 & 0 & 0 & 7 & 43 & 100 & 4.62 & 0 & 0 & 0 & 94 & 56 & 4.37 \\
\hline 3 & Participant Permissions & 0 & 0 & 0 & 23 & 127 & 4.85 & 0 & 0 & 8 & 37 & 105 & 4.65 & 0 & 0 & 0 & 21 & 129 & 4.86 \\
\hline 4 & One-Click Join & 0 & 13 & 20 & $\begin{array}{c}11 \\
5\end{array}$ & 2 & 3.07 & 0 & 28 & 52 & 65 & 5 & 3.31 & 0 & 41 & 40 & 58 & 11 & 3.26 \\
\hline C. & Software Type & & & & & & & & & & & & & & & & & & \\
\hline 1 & Mobile Application & 0 & 0 & 28 & 26 & 96 & 4.45 & 0 & 0 & 11 & 77 & 62 & 4.34 & 0 & 0 & 34 & 16 & 100 & 4.44 \\
\hline 2 & Browser Application & 0 & 3 & 30 & 17 & 100 & 4.43 & 0 & 0 & 10 & 31 & 109 & 4.66 & 0 & 0 & 12 & 30 & 108 & 4.64 \\
\hline 3 & Desktop Application & 0 & 0 & 21 & 30 & 99 & 4.52 & 0 & 0 & 12 & 5 & 133 & 4.80 & 0 & 0 & 9 & 22 & 119 & 4.73 \\
\hline
\end{tabular}


Appendix 2. ZOOM (Users' Survey Data)

\begin{tabular}{|c|c|c|c|c|c|c|c|c|c|c|c|c|c|c|c|c|c|c|c|}
\hline \multicolumn{20}{|c|}{ ZOOM } \\
\hline \multirow{2}{*}{\multicolumn{2}{|c|}{ Ratings }} & \multicolumn{6}{|c|}{ Student } & \multicolumn{6}{|c|}{ Faculty Member } & \multicolumn{6}{|c|}{ Library Professionals } \\
\hline & & 1 & 2 & 3 & 4 & 5 & Avg & 1 & 2 & 3 & 4 & 5 & Avg & 1 & 2 & 3 & 4 & 5 & Avg \\
\hline 1 & Meets Requirements & 0 & 0 & 14 & 21 & 115 & 4.67 & 0 & 0 & 0 & 54 & 96 & 4.64 & 0 & 0 & 11 & 9 & 130 & 4.79 \\
\hline 2 & Ease of Use & 0 & 0 & 0 & 54 & 96 & 4.64 & 0 & 0 & 0 & 19 & 131 & 4.87 & 0 & 0 & 17 & 38 & 95 & 4.52 \\
\hline 3 & Ease of Setup & 0 & 0 & 0 & 27 & 123 & 4.82 & 0 & 0 & 2 & 18 & 130 & 4.85 & 0 & 0 & 6 & 5 & 139 & 4.89 \\
\hline 4 & Ease of Admin & 0 & 0 & 0 & 51 & 99 & 4.66 & 0 & 0 & 19 & 26 & 105 & 4.57 & 0 & 0 & 0 & 49 & 101 & 4.67 \\
\hline 5 & Quality of Support & 0 & 0 & 17 & 71 & 62 & 4.30 & 0 & 0 & 26 & 55 & 69 & 4.29 & 0 & 0 & 21 & 77 & 52 & 4.21 \\
\hline 6 & $\begin{array}{l}\text { Ease of Doing Business } \\
\text { With }\end{array}$ & 0 & 0 & 18 & 15 & 117 & 4.66 & 0 & 0 & 11 & 0 & 139 & 4.85 & 0 & 0 & 0 & 23 & 127 & 4.85 \\
\hline 7 & $\begin{array}{l}\text { Product Direction (\% } \\
\text { positive) }\end{array}$ & 0 & 0 & 0 & 61 & 89 & 4.59 & 0 & 0 & 11 & 92 & 47 & 4.24 & 0 & 0 & 0 & 36 & 114 & 4.76 \\
\hline \multicolumn{20}{|c|}{ Features } \\
\hline A. & Collaboration Tools & & & & & & & & O & & & & & & & & & & \\
\hline 1 & Screen Sharing & 0 & 0 & 0 & 5 & 145 & 4.97 & 0 & 0 & 4 & 8 & 138 & 4.89 & 0 & 0 & 4 & 11 & 135 & 4.87 \\
\hline 2 & Presentation & & & & & & & & 8 & & & & & & & & & & \\
\hline 3 & Whiteboarding & & & & & & & & & & & & & & & & & & \\
\hline 4 & Live Chat & 0 & 0 & 0 & 29 & 121 & 4.81 & 0 & 0 & 9 & 13 & 128 & 4.79 & 0 & 0 & 0 & 24 & 126 & 4.84 \\
\hline 5 & Hand Rise & 0 & 0 & 1 & 39 & 110 & 4.73 & 0 & 0 & 0 & 139 & 11 & 4.07 & 0 & 0 & 0 & 25 & 125 & 4.83 \\
\hline B. & Meeting Coordination & & & ) & & & & & & & & & & & & & & & \\
\hline 1 & Sheduling & 0 & 0 & 3 & 24 & 123 & 4.80 & 0 & 0 & 5 & 55 & 90 & 4.57 & 0 & 0 & 0 & 1 & 149 & 4.99 \\
\hline 2 & Recording & 0 & 0 & 12 & 9 & 129 & 4.78 & 0 & 0 & 0 & 23 & 127 & 4.85 & 0 & 0 & 10 & 18 & 122 & 4.75 \\
\hline 3 & Participant Permissions & 0 & 0 & 0 & 15 & 135 & 4.90 & 0 & 0 & 0 & 28 & 122 & 4.81 & 0 & 0 & 21 & 18 & 111 & 4.60 \\
\hline 4 & One-Click Join & 0 & 14 & 29 & 100 & 7 & 3.67 & 0 & 7 & 7 & 121 & 15 & 3.96 & 0 & 4 & 24 & 109 & 13 & 3.87 \\
\hline C. & Software Type & & & & & & & & & & & & & & & & & & \\
\hline 1 & Mobile Application & 0 & 0 & 12 & 30 & 108 & 4.64 & 0 & 0 & 8 & 45 & 97 & 4.59 & 0 & 0 & 5 & 10 & 135 & 4.87 \\
\hline 2 & Browser Application & 0 & 0 & 24 & 9 & 117 & 4.62 & 0 & 0 & 13 & 17 & 120 & 4.71 & 0 & 0 & 8 & 26 & 116 & 4.72 \\
\hline 3 & Desktop Application & 0 & 0 & 33 & 16 & 101 & 4.45 & 0 & 0 & 0 & 28 & 122 & 4.81 & 0 & 0 & 0 & 19 & 131 & 4.87 \\
\hline
\end{tabular}


Appendix 3. GTM (Users' Survey Data)

\begin{tabular}{|c|c|c|c|c|c|c|c|c|c|c|c|c|c|c|c|c|c|c|c|}
\hline \multicolumn{20}{|c|}{ GTM } \\
\hline \multirow{2}{*}{\multicolumn{2}{|c|}{ Ratings }} & \multicolumn{6}{|c|}{ Student } & \multicolumn{6}{|c|}{ Faculty Member } & \multicolumn{6}{|c|}{ Library Professionals } \\
\hline & & 1 & 2 & 3 & 4 & 5 & Avg & 1 & 2 & 3 & 4 & 5 & Avg & 1 & 2 & 3 & 4 & 5 & Avg \\
\hline 1 & Meets Requirements & 0 & 0 & 14 & 35 & 101 & 4.58 & 0 & 0 & 28 & 24 & 98 & 4.47 & 0 & 4 & 13 & 17 & 116 & 4.63 \\
\hline 2 & Ease of Use & 0 & 0 & 34 & 22 & 94 & 4.40 & 0 & 0 & 37 & 19 & 94 & 4.38 & 0 & 0 & 25 & 46 & 79 & 4.36 \\
\hline 3 & Ease of Setup & 0 & 0 & 28 & 41 & 81 & 4.35 & 0 & 0 & 23 & 19 & 110 & 4.63 & 0 & 0 & 41 & 10 & 99 & 4.39 \\
\hline 4 & Ease of Admin & 0 & 0 & 0 & 147 & 3 & 4.02 & 0 & 0 & 49 & 2 & 99 & 4.33 & 0 & 0 & 38 & 10 & 102 & 4.43 \\
\hline 5 & Quality of Support & 0 & 8 & 26 & 55 & 61 & 4.12 & 0 & 0 & 54 & 88 & 8 & 3.69 & 0 & 20 & 3 & 81 & 46 & 4.02 \\
\hline 6 & $\begin{array}{l}\text { Ease of Doing Business } \\
\text { With }\end{array}$ & 0 & 0 & 37 & 13 & 100 & 4.42 & 0 & 6 & 25 & 29 & 90 & 4.35 & 0 & 0 & 33 & 38 & 79 & 4.31 \\
\hline 7 & $\begin{array}{l}\text { Product Direction (\% } \\
\text { positive) }\end{array}$ & 0 & 15 & 30 & 95 & 10 & 3.66 & 0 & 0 & 72 & 31 & 47 & 3.83 & 0 & 0 & 9 & 118 & 23 & 4.09 \\
\hline \multicolumn{20}{|c|}{ Features } \\
\hline \multicolumn{20}{|c|}{ A. Collaboration Tools } \\
\hline 1 & Screen Sharing & 0 & 0 & 11 & 40 & 99 & 4.59 & 0 & 0 & 8 & 55 & 87 & 4.53 & 0 & 0 & 38 & 9 & 103 & 4.43 \\
\hline 2 & Presentation & 0 & 0 & 0 & 52 & 98 & 4.65 & 0 & 0 & 22 & 25 & 103 & 4.54 & 0 & 0 & 34 & 15 & 101 & 4.45 \\
\hline 3 & Whiteboarding & 0 & 0 & 30 & 61 & 59 & 4.19 & 0 & 0 & 35 & 10 & 105 & 4.47 & 0 & 0 & 41 & 66 & 43 & 4.01 \\
\hline 4 & Live Chat & 0 & 0 & 24 & 36 & 90 & 4.44 & 0 & 0 & 18 & 73 & 59 & 4.27 & 0 & 0 & 16 & 37 & 97 & 4.54 \\
\hline 5 & Hand Rise & 0 & 0 & 4 & 42 & 104 & 4.67 & 0 & 0 & 11 & 44 & 95 & 4.56 & 0 & 0 & 7 & 24 & 119 & 4.75 \\
\hline \multirow[t]{2}{*}{ B. } & Meeting Coordination & & & ) & & & & & & & & & & & & & & & \\
\hline & Sheduling & 0 & 0 & 20 & 32 & 98 & 4.52 & 0 & 8 & 0 & 46 & 96 & 4.53 & 0 & 0 & 19 & 60 & 71 & 4.61 \\
\hline 2 & Recording & 0 & 0 & 4 & 94 & 52 & 4.32 & 0 & 0 & 0 & 107 & 43 & 4.29 & 0 & 0 & 50 & 10 & 90 & 4.27 \\
\hline 3 & Participant Permissions & 0 & 0 & 31 & 23 & 96 & 4.43 & 0 & 0 & 13 & 47 & 90 & 4.51 & 0 & 0 & 20 & 48 & 82 & 4.41 \\
\hline 4 & One-Click Join & 0 & 0 & 78 & 53 & 19 & 3.61 & 0 & 0 & 69 & 80 & 1 & 3.54 & 0 & 0 & 71 & 23 & 56 & 3.52 \\
\hline \multicolumn{20}{|c|}{ C. Software Type } \\
\hline 1 & Mobile Application & 0 & 0 & 33 & 69 & 48 & 4.10 & 0 & 0 & 29 & 65 & 56 & 4.18 & 0 & 2 & 25 & 73 & 50 & 4.14 \\
\hline 2 & Browser Application & 0 & 3 & 71 & 8 & 71 & 4.00 & 0 & 10 & 19 & 70 & 51 & 4.08 & 0 & 0 & 44 & 47 & 59 & 4.10 \\
\hline 3 & Desktop Application & 0 & 0 & 15 & 59 & 76 & 4.41 & 0 & 0 & 0 & 93 & 57 & 4.38 & 0 & 6 & 12 & 41 & 91 & 4.45 \\
\hline
\end{tabular}


Appendix 4. Join.me (Users' Survey Data)

\begin{tabular}{|c|c|c|c|c|c|c|c|c|c|c|c|c|c|c|c|c|c|c|c|}
\hline \multicolumn{20}{|c|}{ Join.me } \\
\hline SN & \multirow[b]{2}{*}{ Ratings } & \multicolumn{6}{|c|}{ Student } & \multicolumn{6}{|c|}{ Faculty Member } & \multicolumn{6}{|c|}{ Library Professionals } \\
\hline & & 1 & 2 & 3 & 4 & 5 & Avg & 1 & 2 & 3 & 4 & 5 & Avg & 1 & 2 & 3 & 4 & 5 & Avg \\
\hline 1 & Meets Requirements & 0 & 0 & 25 & 31 & 94 & 4.46 & 0 & 0 & 28 & 37 & 85 & 4.38 & 0 & 0 & 7 & 51 & 92 & 4.56 \\
\hline 2 & Ease of Use & 0 & 0 & 13 & 46 & 91 & 4.52 & 0 & 0 & 10 & 27 & 113 & 4.69 & 0 & 0 & 17 & 33 & 100 & 4.55 \\
\hline 3 & Ease of Setup & 0 & 0 & 15 & 40 & 95 & 4.53 & 0 & 0 & 6 & 34 & 110 & 4.69 & 0 & 0 & 20 & 39 & 91 & 4.47 \\
\hline 4 & Ease of Admin & 0 & 0 & 19 & 41 & 90 & 4.47 & 0 & 0 & 8 & 46 & 96 & 4.59 & 0 & 0 & 14 & 41 & 95 & 4.54 \\
\hline 5 & Quality of Support & 0 & 10 & 24 & 71 & 45 & 4.01 & 0 & 5 & 20 & 79 & 46 & 4.11 & 0 & 0 & 28 & 83 & 39 & 4.07 \\
\hline 6 & Ease of Doing Business With & 0 & 0 & 45 & 30 & 75 & 4.20 & 0 & 0 & 33 & 41 & 76 & 4.29 & 0 & 0 & 23 & 47 & 80 & 4.38 \\
\hline 7 & Product Direction (\% positive) & 0 & 6 & 18 & 76 & 50 & 4.13 & 0 & 15 & 18 & 73 & 44 & 3.97 & 0 & 0 & 44 & 48 & 58 & 4.09 \\
\hline & Features & & & & & & & & & & & 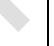 & & & & & & & \\
\hline A. & Collaboration Tools & & & & & & & & & & & & & & & & & & \\
\hline 1 & Screen Sharing & 0 & 0 & 12 & 30 & 108 & 4.64 & 0 & 0 & 5 & 44 & 101 & 4.64 & 0 & 0 & 14 & 41 & 95 & 4.54 \\
\hline 2 & Presentation & 0 & 0 & 16 & 28 & 106 & 4.60 & 0 & 0 & 17 & 33 & 100 & 4.55 & 0 & 0 & 19 & 26 & 105 & 4.57 \\
\hline 3 & Whiteboarding & 0 & 0 & 15 & 14 & 121 & 4.71 & 0 & 0 & 11 & 19 & 120 & 4.73 & 0 & 0 & 0 & 28 & 122 & 4.81 \\
\hline 4 & Live Chat & 0 & 0 & 0 & 27 & 123 & 4.82 & 0 & 0 & 4 & 26 & 120 & 4.77 & 0 & 0 & 0 & 32 & 118 & 4.79 \\
\hline 5 & Hand Rise & & & & & & & & & & & & & & & & & & \\
\hline B. & Meeting Coordination & & & & & & & & & & & & & & & & & & \\
\hline 1 & Sheduling & 0 & 0 & 19 & 22 & 109 & 4.60 & 0 & 0 & 13 & 50 & 87 & 4.49 & 0 & 0 & 9 & 39 & 102 & 4.62 \\
\hline 2 & Recording & 0 & 0 & 22 & 28 & 100 & 4.52 & 0 & 0 & 19 & 40 & 91 & 4.48 & 0 & 0 & 12 & 60 & 78 & 4.44 \\
\hline 3 & Participant Permissions & 0 & 0 & 17 & 23 & 110 & 4.62 & 0 & 0 & 14 & 40 & 96 & 4.55 & 0 & 0 & 11 & 31 & 109 & 4.68 \\
\hline 4 & One-Click Join & 0 & 0 & 6 & 50 & 94 & 4.59 & 0 & 0 & 5 & 35 & 110 & 4.70 & 0 & 4 & 40 & 11 & 105 & 4.65 \\
\hline C. & Software Type & & & & & & & & & & & & & & & & & & \\
\hline 1 & Mobile Application & 0 & 0 & 19 & 91 & 40 & 4.14 & 0 & 10 & 14 & 66 & 60 & 4.17 & 0 & 6 & 19 & 63 & 62 & 4.21 \\
\hline 2 & Browser Application & 0 & 10 & 10 & 32 & 98 & 4.45 & 0 & 0 & 15 & 40 & 95 & 4.53 & 0 & 0 & 20 & 38 & 92 & 4.48 \\
\hline 3 & Desktop Application & 0 & 0 & 14 & 56 & 80 & 4.44 & 0 & 2 & 22 & 31 & 95 & 4.46 & 0 & 0 & 9 & 47 & 94 & 4.57 \\
\hline
\end{tabular}


Usefulness of Free Conference Call (FCC) in Digital Learning Platform: A Comparative Study using Users' Perception and Economical Compatibility

Appendix 5. Cisco Webex (Users' Survey Data)

\begin{tabular}{|c|c|c|c|c|c|c|c|c|c|c|c|c|c|c|c|c|c|c|c|}
\hline \multicolumn{20}{|c|}{ Cisco Webex } \\
\hline SN & \multirow[b]{2}{*}{ Ratings } & \multicolumn{6}{|c|}{ Student } & \multicolumn{6}{|c|}{ Faculty Member } & \multicolumn{6}{|c|}{ Library Professionals } \\
\hline & & 1 & 2 & 3 & 4 & 5 & Avg & 1 & 2 & 3 & 4 & 5 & Avg & 1 & 2 & 3 & 4 & 5 & Avg \\
\hline 1 & Meets Requirements & 0 & 0 & 16 & 33 & 101 & 4.57 & 0 & 0 & 25 & 17 & 108 & 4.55 & 0 & 0 & 11 & 40 & 99 & 4.59 \\
\hline 2 & Ease of Use & 0 & 0 & 0 & 46 & 104 & 4.69 & 0 & 0 & 13 & 34 & 103 & 4.60 & 0 & 0 & 12 & 32 & 106 & 4.63 \\
\hline 3 & Ease of Setup & 0 & 0 & 19 & 48 & 83 & 4.43 & 0 & 2 & 10 & 42 & 96 & 4.55 & 0 & 0 & 31 & 15 & 104 & 4.49 \\
\hline 4 & Ease of Admin & 0 & 0 & 18 & 33 & 99 & 4.54 & 0 & 0 & 15 & 44 & 91 & 4.51 & 0 & 0 & 20 & 35 & 95 & 4.50 \\
\hline 5 & Quality of Support & 0 & 0 & 11 & 79 & 60 & 4.33 & 0 & 0 & 14 & 70 & 66 & 4.35 & 0 & 0 & 25 & 77 & 48 & 4.15 \\
\hline 6 & Ease of Doing Business With & 0 & 0 & 10 & 82 & 58 & 4.32 & 0 & 0 & 15 & 48 & 87 & 4.48 & 0 & 0 & 19 & 67 & 64 & 4.30 \\
\hline 7 & Product Direction ( $\%$ positive) & 0 & 0 & 24 & 85 & 41 & 4.11 & 0 & 0 & 20 & 89 & 41 & 4.14 & 0 & 0 & 24 & 82 & 44 & 4.13 \\
\hline & Features & & & & & & & & & & & 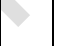 & & & & & & & \\
\hline A. & Collaboration Tools & & & & & & & & & 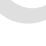 & & & & & & & & & \\
\hline 1 & Screen Sharing & 0 & 0 & 9 & 20 & 121 & 4.75 & 0 & 0 & 2 & 29 & 119 & 4.78 & 0 & 0 & 11 & 14 & 125 & 4.76 \\
\hline 2 & Presentation & 0 & 0 & 19 & 11 & 120 & 4.67 & 0 & 0 & 25 & 3 & 122 & 4.65 & 0 & 0 & 29 & 5 & 116 & 4.58 \\
\hline 3 & Whiteboarding & 0 & 0 & 31 & 39 & 80 & 4.33 & 0 & 0 & 40 & 20 & 90 & 4.33 & 0 & 0 & 20 & 64 & 66 & 4.31 \\
\hline 4 & Live Chat & 0 & 0 & 20 & 33 & 97 & 4.51 & 0 & 0 & 14 & 36 & 100 & 4.57 & 0 & 0 & 13 & 40 & 97 & 4.56 \\
\hline 5 & Hand Rise & 0 & 1 & 11 & 30 & 108 & 4.63 & 0 & 0 & 22 & 18 & 110 & 4.59 & 0 & 0 & 15 & 30 & 105 & 4.60 \\
\hline B. & Meeting Coordination & & & & & & & & & & & & & & & & & & \\
\hline 1 & Sheduling & 0 & 0 & 16 & 34 & 100 & 4.56 & 0 & 0 & 10 & 45 & 95 & 4.57 & 0 & 0 & 9 & 42 & 98 & 4.57 \\
\hline 2 & Recording & 0 & 0 & 12 & 42 & 96 & 4.56 & 0 & 0 & 17 & 40 & 97 & 4.64 & 0 & 2 & 10 & 44 & 94 & 4.53 \\
\hline 3 & Participant Permissions & 0 & 0 & 13 & 33 & 104 & 4.61 & 0 & 0 & 15 & 32 & 103 & 4.59 & 0 & 0 & 10 & 29 & 111 & 4.67 \\
\hline 4 & One-Click Join & 0 & 0 & 20 & 38 & 92 & 4.48 & 0 & 0 & 27 & 22 & 101 & 4.49 & 0 & 0 & 19 & 33 & 98 & 4.53 \\
\hline C. & Software Type & & & & & & & & & & & & & & & & & & \\
\hline 1 & Mobile Application & 0 & 0 & 18 & 67 & 65 & 4.31 & 0 & 0 & 15 & 71 & 64 & 4.33 & 0 & 0 & 21 & 59 & 70 & 4.33 \\
\hline 2 & Browser Application & 0 & 0 & 10 & 108 & 32 & 4.15 & 0 & 6 & 5 & 104 & 35 & 4.12 & 0 & 0 & 4 & 110 & 36 & 4.21 \\
\hline 3 & Desktop Application & 0 & 3 & 30 & 17 & 100 & 4.43 & 0 & 0 & 12 & 5 & 133 & 4.80 & 0 & 0 & 9 & 22 & 119 & 4.73 \\
\hline
\end{tabular}




\section{Author}

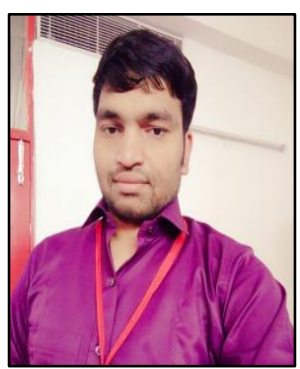

\section{Mr Subhajit Panda}

Mr Subhajit Panda, currently working as an Assistant Librarian in the Central Library, Chandigarh University. He has 6 National Publication, 1 International Publication, 2 Book Chapter, and present a paper in 9 National Conferences. Skilled in Digital Literacy, Information Retrieval, Library Management, Bookkeeping, and Referencing. His areas of interests are e-Learning, Cloud Computing, Open Access, Web Accessibility, Virtual \& Augmented Reality and Metrics Studies. 
Usefulness of Free Conference Call (FCC) in Digital Learning Platform: A Comparative Study using Users' Perception and Economical Compatibility

This page is empty by intention. 